\title{
Happinomics among Factors of Production using a Principal Component Analysis Approach: A Case Study of Labour and Entrepreneurs' Subjective Happiness in
} KwaZulu-Natal, South Africa

\section{Professor Darma Mahadea}

\author{
School of Economics and Finance, \\ University of KwaZulu-Natal, South Africa \\ Email: mahadead@ukzn.ac.za
}

\author{
Doi:10.5901/mjss.2014.v5n4p99
}

\begin{abstract}
Amidst the recent global financial crisis, there is a surge of interest in happiness. All of us want to have satisfying lives. Yet, not everybody is happy, even among the wealthy. Believing that happiness lies through the satisfaction of physical desires and material possessions, many individuals work hard to earn income, often at the expense of leisure and good social relationships. This paper examines the determinants of subjective well-being of entrepreneurs and workers as a group in a South African province, using the principal component approach. Various components emerged as happiness--influencing factors, jointly explaining about 70 per cent of the variation in self-reported well-being. These sets are related to asset ownership, family togetherness and personal attributes, household characteristics, human and social capital, future financial security (pension), work relationships, and community involvement. Religion and creativity account for almost a tenth of the variation in subjective well-being. Income is relevant but not found to be the main determinant of a satisfying life.
\end{abstract}

Keywords: Happiness, subjective well-being, labour, entrepreneur, income, relationships, social capital, community network, work environment.

\section{Introduction}

The quest for individual happiness and a better life is sought after in both developed and developing countries. All of us want to be happy and lead flourishing lives of lasting fulfillment. Yet, not everybody is happy. Formerly, happiness or subjective well-being was a major research interest for philosophers. In recent times, the 'science of happiness' has attracted the interest of some psychologists, economists, politicians and neuroscientists (Dixon, 1997; Layard, 2011).

Psychologists are examining happiness through brain signals, personality traits and environmental factors. Philosophers probe happiness by looking at the maximization of pleasure and virtuous human qualities that contribute to a good eudemonic life (Bruni and Porta, 2007). Our experience of well-being is greatly influenced by our connections with other people. Accordingly, social scientists consider the influence of friendships, family relationships and communities on happiness. Economists focus on the influence of consumption, wealth and economic growth on well-being (Dutt and Radcliff, 2009; Sachs, 2012).

It is popularly believed that happiness increases when people consume more goods and services with rising income. The more income individuals earn, the greater the number of needs can be satisfied, resulting in greater levels of utility. As income is earned primarily through employment, many individuals seek happiness by working for long hours to gain money often at the expense of leisure and good social relations. They believe that happiness lies in the satisfaction of physical desires and in obtaining ever more material possessions.

As economic growth increases real per capita income, people can afford to buy more superior goods and services. The higher income gains contribute to poverty alleviation and enhanced life satisfactions (Layard, 2006).

It is thus no surprise that the pursuit of happiness is a constitutional right of the American citizen since the days of Thomas Jefferson in 1776. In August 2011, the UN recognized 'happiness as a universal goal and aspiration' (Nuthall, 2013). In recent times, top policy-makers, in countries as different as Brazil and Britain seem to support the measurement of gross national happiness (GNH) rather than GDP as a measure of prosperity (Porter, 2011). Pursuing GNH rather than GDP seems to have yielded positive contentment results in Bhutan in the past decades (Sachs, 2012). The New Economics Foundation suggests the Happy Planet Index as a measure of national well-being. This index consists of a country's life satisfaction, life expectancy and ecological footprint per capita as an indicator of prosperity. 
South Africa does not seem to score well on happiness, according to this index. Indeed, according to the World Database of Happiness, the average level of happiness or life satisfaction in South Africa decreased from 6.8 in 2006 to 6.31 in 2007 and to 4.95 in 2008 (Veenhoven, 2012). This reflects that people there have experienced, on average, a reduced level of life satisfaction in recent years.

At the individual level, various factors contribute to subjective well-being. This paper examines primarily the influences on happiness on the basis of a survey that involves a subjective assessment of the respondents' well-being in central Pietermaritzburg, the capital of the Kwazulu-Natal province, in South Africa. As a secondary objective, the paper examines whether, on average, self-reported happiness varies by gender, occupation and marital status. The paper consists of four sections. Following the introduction, there is a literature review on happiness. The second section highlights the research methodology. This is followed by a description of the sample characteristics, descriptive results and findings of the factor and principal component analyses. The final section presents a discussion of the findings and some policy implications.

\section{Literature Review: Economic and Philosophical Foundations}

Happiness is not defined in a uniform way (Porter, 2011). Veenhoven (1993) defines happiness as the degree to which an individual judges the overall quality of his or her life as being favourable. Viewed narrowly, happiness is associated with hedonism, a mental state of feeling good or brief feelings of pleasure, and avoidance of pain (Kahneman, 2012). To Aristotle, happiness is a form of the good life associated with virtuous activities and moral actions, and it is the highest good (supreme goal) of all things we seek in life for its own sake and never for something else (O'Toole, 2005). Accordingly, Jeremy Bentham, the founder of the Utilitarian philosophy, argues that the individual's conduct as well as government policies should be directed toward promoting the greatest happiness for the greatest number of people and minimizing pain. Similarly, while promoting the idea that more wealth leads to happiness, Adam Smith (1759:232), postulated that leaders should "secure the internal tranquility and happiness" of their fellow-citizens.

Economics has traditionally viewed happiness in terms of subjective well-being, which is regarded as a proxy for utility (Frey and Stutzer, 2000). Ng (2006) defines happiness as 'welfare'. Oswald (1997) views happiness as 'pleasure' or 'satisfaction'. Layard (2011) regards happiness as enjoying life and feeling good with reflective cognitive evaluations, synonymous with subjective well-being (SWB). Individuals are said to have high SWB if they experience high life satisfactions and frequent pleasant emotions such as joy and affection, and only infrequently experience unpleasant emotions. Easterlin (2001: 465) views happiness in a broader way: "I use the terms happiness, subjective well-being, satisfaction, utility, welfare interchangeably." The terms of these social scientists on happiness are used in this study.

Economic literature suggests a link between happiness and income, particularly in societies with low real per capita GDP. Recent studies show that happiness increases with income and entire nations can be happier with an expansion in economic growth (Kenny, 2005; Veenhoven and Hagerty, 2006). People with higher incomes have a higher status in society, intrinsically making them happy and enabling them to buy positional goods. These are expensive goods that are scarce and the ability to afford them is limited to wealthy individuals; in this absolute or socially imposed sense "income does buy happiness" (Frey and Stutzer, 2002: 40). High income earners can augment their own happiness and that of poorer people too through their generous donations of money to less privileged individuals and charitable organizations. As Aristotle puts in, there is greater pleasure in giving than in selfishness, as this strengthens an individual on the path to virtue and happiness (O'Toole, 2005).

The behavioural school and Daniel Kahneman, the Nobel Prize winner for Economics in 2002, treat happiness as a subjective issue that is measurable through surveys. This is possible by asking respondents, for example, how happy they are on a scale (1 to 10), at a given moment and over time (Seligman, 2004). Frey and Stutzer (2002: 405) argue that in evaluating happiness in relation to income and other factors, it is sensible in Economics to rely on the judgments of people as they are regarded to be the best judges of the overall quality of their own lives. Stutzer (2001:37) asserts that the measures of subjective well-being have a "high consistency, reliability and validity", as well as high stability over time. Recent advances in brain scans have helped neuroscientists identify the left part of the central nervous system as most stimulated by happiness and these findings add a layer of scientific credibility to measures of happiness (Layard, 2011).

\subsection{Income and Happiness}

Each individual wants money, not for its own sake, but for what it can bring to us in terms of happiness (Ng, 1997). Income and its increase, matter a lot to happiness when individuals are in poverty. In developing countries, higher 
income raises the happiness of poor people living below the bread line, enabling them to meet basic needs. Individuals, on average, in wealthier countries are happier than those in poorer countries, and this relationship between happiness and income holds at a particular point in time and in a given country (Easterlin, 1995; Kenny, 2005). But long-term studies on happiness in developed countries indicate that people there, on average, are currently no happier than in earlier times, although their real incomes have increased significantly and they are richer (Easterlin, 1995; Frey and Stutzer, 2002). According to Layard (2011), once a nation's average salary exceeds $\$ 20000$ a year, diminishing returns of happiness beyond that income level seem to set in. This income-happiness nexus seems like a paradox.

Absolute income matters to individual happiness up to a point, but once basic needs are met, relative income matters more for happiness (Easterlin, 2001: 481; Mahadea and Rawat, 2008). People compare their incomes and style of living with those of others in the income distribution, when evaluating their current level of subjective well-being. Studies in South Africa have also found that relative income is an important determinant of subjective well-being (Posel and Casale, 2011; Hinks and Gruen, 2007).

If people's aspirations do not change, a rise in income may increase subjective happiness. But as people earn higher levels of income, their aspirations usually change and many end up on a 'hedonic treadmill', continuously endeavoring to achieve more. Feeling unsatisfied with what they have, individuals often desire to possess more material goods and indulge in conspicuous consumption, possibly by contracting debt. High levels of debt impact on savings and reduce household happiness (Dutt, 2008). Some individuals emulate the habits of celebrities or others, prompting them to buy more. This is partly because of advertising or consumerism, and the need to "keep up with the Joneses". Although many persons catch the 'luxury fever', this 'affluenza' does not necessarily make them permanently happier (James, 2007; Frank, 1999); it possibly contributes to a "joyless society" (Scitovsky, 1992). Status competitions or consumption can make individuals vulnerable to depression, anxiety, substance abuse and personality disorders, all of which detract from happiness (Wilkinson and Pickett, 2010).

Inequalities and poverty have negative effects on reported happiness in South Africa and other countries too (Posel and Casale, 2011; Sachs, 2012). Societies with low income inequalities tend to be happier, with high levels of trust (Wilkinson and Pickett, 2010). Indeed, according the Human Development Report (2011), South Africa's perceived well-being or overall life satisfaction index over the period 2006-2010, was a low 4.7, which is below the average (4.9) of countries in a similar development group, and below the global average figure, 5.3.

\subsection{Work and Happiness}

Quality of relationships one has at work has a bearing on individual happiness. Individuals earn an income primarily from supplying their labour services and talents to the market. If we do not work or do not have a regular source of income, we may enjoy considerable leisure, but limited satisfaction without money. Some individuals choose to work for an income as an employee, whereas others tend to create employment for themselves as entrepreneurs. The latter venture into risk-taking activities by starting up a business to provide a good or service, and in the process create employment for themselves and for others. These risk-takers earn a flexible income, depending on the prosperity of the firm. Some entrepreneurs go into business by necessity, in that they are 'forced' to go into self-employment because of lack of alternative employment opportunities, whereas others choose this path because of attractive income or non-income rewards and opportunistic opportunities. Thus, those who are in employment and enjoy their work are happier than those who are unemployed (Clark and Oswald, 1994).

In a working environment, that offers scope for the individual to grow, to participate in decision-making, employees feel respected and happy for their ideas and contributions to the firm. Happy workers are good workers. Satisfaction at work impacts positively on employee motivation, productivity and business performance (Frey, 2008; Diener and BiswasDiener, 2008). Workers with stronger support and social networks have more meaningful interactions with coworkers. They are more involved in group projects and experience greater flow with gratifications at work. They tend to be thriving and loyal to their firm (Sachs, 2012; Csikszentmihalyi, 1997).

\subsection{Socio-demographic and Personality Influences on Happiness}

People with more education and capabilities are generally more productive and earn more; they tend to be happier than those with less education (Sen, 2010). Hinks and Gruen (2007) found that individuals in South Africa with tertiary education are happier than those with little education. The nature of relationships one has in the community and family environment has a bearing on individual happiness. Individuals with a greater social connectivity are less isolated, better 
supported, more bonded and thus happier (Putman, 2001; Lane, 2001). Individuals with better family ties, with children and friendships, and living in a good or safe community environment, are happier than others where these qualities are lacking. Thus, social capital impacts on the well-being of individuals (Dutt and Radcliff, 2009; Powdthavee, 2007).

Further, studies show that people who have good health and who are more extroverted are happier than others (Diener and Seligman, 2002; Layard, 2011). Women, on average, tend to be happier than men, but they also tend to have higher rates of mental disorder than men (Frey and Stutzer, 2002; Wilkinson and Pickett, 2010). Intrinsic religious commitment tends to have a positive effect on life satisfaction as it often promotes virtuosity, spirituality and the values of caring for others and mankind (Perkins, 1991; Rule, 2007). Further, married people tend to be happier than single, divorced and widowed persons (Oswald 1997; Layard, 2011). Happier people are more likely to get married and stay married, and have richer networks of friends and social support (Diener and Biswas-Diener, 2008; Putman, 2001). Powdthavee $(2007,2011)$ found that South Africans in civil marriages are significantly happier than people who are single and have never married.

\section{Research Objectives}

The primary objective is to evaluate the factors that are associated with happiness of labour and entrepreneurs as one group in the South African province of KwaZulu-Natal (KZN). The secondary objective is to examine whether subjective well-being varies by gender, ethnicity, occupation and marital status.

\subsection{Research Methodology}

Researchers need to gather information on different life domains to understand what makes for happiness (Veenhoven, 1997). Relevant data on the levels of self-reported happiness of the surveyed entrepreneurs and employees, as well as on other attributes, were obtained by administering a pre-tested questionnaire in central Pietermaritzburg. The question on self-reported happiness has evident face validity. It is the subjects who make the appraisal of their subjective wellbeing or happiness, and who are the best judges of their true level of life satisfaction.

The sample consisted of 300 subjects, selected by judgmental and convenience sampling. There were 70 entrepreneurs, randomly chosen from a list of the small firm entrepreneurs, obtained from the Pietermaritzburg Chamber of Commerce, and 230 employees randomly chosen from various firms. To avoid any bias, the employees of the surveyed entrepreneurs' firms were not selected.

Consistent with other studies (Powdthavee, 2011; Seligman, 2004), happiness was measured on a Likert scale, from 1 to 5, with lower values indicating least happy (1) and higher values reflecting extremely happy (5). Income was measured along a continuum from low (R1000) to high (R18000 and above).

The questionnaire administered, through face-to-face interviews, also sought information on the respondents' income, education, car and house ownership, pension and medical aid, relationships and demographic background. Questions relating to their health, work environment, debt, friendships, and religion were measured on a Likert scale, enabling respondents to indicate their opinions on how strongly each factor influenced their personal happiness. The scale ranged from 1 to 10, with low values reflecting no or low importance and highest value (10) indicating most important.

Similarly, questions relating to work environment and community involvement were measured on a five point-point Likert scale. All these variables were treated as categorical factors. To ensure validity that the data collected adequately capture a person's true subjective well-being, the survey questionnaire was developed by reviewing literature, adapting items from previous studies, especially by Seligman (2004) and Layard (2011), discussing with experts in the happiness field and a pilot pre-testing with some relevant members.

Reliability is the consistency of a questionnaire. It can be reflected by the Cronbach's alpha. In this case, the Cronbach's alpha relating to work environment items was a high 0.817 , indicating a strong internal consistency; but for all the items on the questionnaire the alpha value was just under 0.7. Although values of the Cronbach's alpha greater than 0.7 are deemed to indicate a good overall reliability a slightly lower value is acceptable (Coakes and Steed, 2003).

The data was analysed using SPSS. The relationship between happiness and the above variables was examined using a factor analysis and principal component analysis. The usual t-test was used to examine whether mean happiness varies with marital status and whether there are differences in average happiness level between gender, occupation and ethnic groups. The results are presented in two stages: the descriptive findings and the t-test results are shown first, and then outcomes of the factor and principal analyses. 


\subsection{Sample Particulars}

The sample size, consisting of 130 male (43\%) and 170 female (57\%), is rather limited. The ethnicity of the respondents were as follows: 68 black, including one entrepreneur, 17 coloured, including 2 entrepreneurs, 49 indian, including 7 entrepreneurs, and the remainder were white and the latter category included 65 entrepreneurs. With regard to age, 64 were in the 18-30 group, 115 in the 31- 45 group, 91 in the 46-59 category group and 30 were between 60 and 75 .

\section{Descriptive and Test Results}

The majority of the people surveyed reported to be happy. Only 8.6\% reported being 'not happy at all' or 'not very happy', $34.3 \%$ reported being 'fairly happy' and $40.3 \%$ reported being 'very happy' and the remainder (almost 17\%) reported being "extremely happy." Subjective well-being varied among different ethnic and occupational groups. On average, the black respondents reported a lower level (3.1) of happiness relative to the white (3.7) subjects and the difference between the two groups was significant $(t=-4.732 ; p=0.000)$. Further, the entrepreneurs, as self-employed respondents, with an average happiness score of 3.9 , were significantly happier than the wage-employed respondents, who had an average score of $3.5(t=-3.80 ; p=0.000)$.

Their gross monthly income ranged from R1000 to R18000 and over. In the low income group R1000- 2000, there were $10.7 \%$ of the respondents, $8 \%$ in the R2001-R4000 group; $29.3 \%$ earned between R4000 and R10000, $23.3 \%$ earned between R10001-R18000 group, and about 29\% earned over R18000.

The level of education of the respondents ranged from grade 4 to the postgraduate level. Of the respondents, $10 \%$ had an education level between grade 4 and grade $11,41 \%$ had a matric pass, 26\% had a diploma, 12\% had a university degree or tertiary education and $11 \%$ had a postgraduate education.

Women reported an average happiness level (3.54) that is marginally lower than that of the men (3.68). Although the average happiness level of the males was higher that of the females, the difference was not found to be significant ( $t$ $=1.23 ; p=0.219)$. The male and female respondents thus experience about the same mean level of happiness.

Of the surveyed subjects, almost 56\% (167) were married and 11\% (32) were divorced, with the remainder being single or widowed. Married people are reportedly happiest, with a mean happiness score of 3.72. Single people had a mean happiness score of 3.50, divorced people had a mean happiness level of 3.37 and widowed people had an average happiness score of 3 . The results indicate that the surveyed married individuals are happier than their divorced or single counterparts and the result is significant $(t=1.934, p=0.05)$. This perhaps reflects the importance of having a fulfilled married life as critical to happiness, and the dissolution of a union as a potential cause (or result) of unhappiness, as also argued by Layard and Oswald. Indeed, according to the World Values Survey on happiness, a disruption or dissolution of a union can lead to a fall of 8 points (on a scale of 10 to 100) in happiness of individuals (Layard, 2011).

\subsection{Results of the Principal Component and Factor Analyses}

To capture the significance of the factors influencing perceived happiness of all the respondents as a group, a factor analysis and a Principal Components analysis with Varimax Kaiser normalization are undertaken. The factor analysis is used to reduce a large number of variables to a smaller set of underlying factors that can explain happiness. In this study, all 21 items were factor analysed, using the principal component analysis. The principal component analysis decomposes the original data into a set of linear variables and shows how a particular variable might contribute to that component (Field, 2009). This principal component approach is suitable because it takes into account unobserved variability in the measured variables. It was assumed that entrepreneurs and labour are a homogenous group in terms of the common quest for happiness and hence treated as one group for the factor analysis. The mean and standard deviation of the factors are presented in Table 1, with high average values for health (9.2), family togetherness (9.1), leisure (8.6) and work environment (8.06). 
Table 1: Descriptive Statistics: Mean Happiness Levels

\begin{tabular}{|l|c|c|}
\hline \multicolumn{1}{|c|}{ Perceived Happiness Factors } & Mean & Std. Deviation \\
\hline Friends at work & 3.2133 & 1.43596 \\
Treat at work & 4.1600 & 1.01396 \\
Ideas contribution & 5.6800 & 1.30150 \\
Personal growth work & 4.0400 & .95068 \\
Community programs & 3.2400 & 1.19503 \\
Necessity choice & 1.7067 & .45836 \\
Community friends & 7.8400 & 2.28414 \\
Education & 7.1200 & 2.48215 \\
Family unity togetherness & 9.1333 & 1.76554 \\
Health condition & 9.2000 & 1.39497 \\
Income received & 7.0800 & 2.24066 \\
Work environment & 8.0667 & 1.86962 \\
Debt owe & 5.2800 & 3.61887 \\
Children number & 5.8667 & 3.47708 \\
Leisure freedom & 8.6667 & 1.63023 \\
Religion faith & 5.4400 & 3.65853 \\
Medical aid & 1.2533 & .43785 \\
Pension fund & 1.3200 & .46962 \\
Car ownership & 1.0800 & .27312 \\
Household durable items & 1.2533 & .43785 \\
House ownership & 1.0667 & .25112 \\
\hline
\end{tabular}

Table 2: KMO and Bartlett's Test

\begin{tabular}{|lc|c|}
\hline Kaiser-Meyer-Olkin Measure of Sampling Adequacy. & .614 \\
Bartlett's Test of Sphericity & Approx. Chi-Square & 377.988 \\
& Df & 210 \\
& Sig. & .000 \\
\hline
\end{tabular}

The factorability of the whole set of variables is ascertained by the Kaiser-Meyer-Olkin (KMO) measure of sampling adequacy and the Bartlett's test. In this study, the KMO value is 0.614 (Table 2) and the Bartlett's test is significant ( $p=$ 0.000; Chi-square value at 377.9), thus supporting the use of the principal components method. The factor analysis, often used interchangeably as a principal components analysis by researchers (Palant, 2006), gives us the most influential factors influencing subjective well-being. However, it must be pointed out the factor analysis is not about causality; it is about finding groupings of similar variables that are correlated into principal component groups, related in this case to happiness. Using the Kaiser' criterion, only components that have an Eigen value greater than 1 are considered.

Accordingly, a set of nine components emerged with Eigen values of 1 or more, jointly explaining almost $70 \%$ of the variation in subjective well-being (Table 3). The first component, consisting of three factors, has an Eigen value of 3.205 , and it explained $15 \%$ of the variation in happiness (Table 3). The two factors of substantive importance influencing happiness in this set are car- and house ownership; entrepreneurship by necessity was found to be negatively related to happiness (Table 4). This negative relationship could be due to forced rather than opportunistic entry into entrepreneurship owing to lack of employment opportunities.

Table 3: Total Variance Explained

\begin{tabular}{|c|c|c|c|c|c|c|c|c|c|}
\hline \multirow{2}{*}{ Component } & \multicolumn{3}{|c|}{ Initial Eigenvalues } & \multicolumn{3}{c|}{ Extraction Sums of Squared Loadings } & \multicolumn{3}{c|}{ Rotation Sums of Squared Loadings } \\
\cline { 2 - 10 } & Total & $\%$ of Variance & Cumulative \% & Total & $\%$ of Variance & Cumulative \% & Total & $\%$ of Variance & Cumulative \% \\
\hline 1 & 3.205 & 15.260 & 15.260 & 3.205 & 15.260 & 15.260 & 2.038 & 9.704 & 9.704 \\
\hline 2 & 2.208 & 10.512 & 25.772 & 2.208 & 10.512 & 25.772 & 1.967 & 9.367 & 19.071 \\
\hline 3 & 1.703 & 8.110 & 33.882 & 1.703 & 8.110 & 33.882 & 1.901 & 9.054 & 28.125 \\
\hline 4 & 1.569 & 7.470 & 41.353 & 1.569 & 7.470 & 41.353 & 1.678 & 7.992 & 36.117 \\
\hline 5 & 1.390 & 6.617 & 47.970 & 1.390 & 6.617 & 47.970 & 1.615 & 7.692 & 43.809 \\
\hline
\end{tabular}




\begin{tabular}{|c|c|c|c|c|c|c|c|c|c|}
\hline 6 & 1.320 & 6.288 & 54.258 & 1.320 & 6.288 & 54.258 & \begin{tabular}{|l|}
1.497 \\
\end{tabular} & 7.127 & 50.936 \\
\hline 7 & 1.197 & 5.702 & 59.959 & 1.197 & 5.702 & 59.959 & 1.446 & 6.885 & 57.821 \\
\hline 8 & 1.040 & 4.955 & 64.914 & 1.040 & 4.955 & 64.914 & 1.405 & 6.689 & 64.510 \\
\hline 9 & 1.016 & 4.838 & 69.752 & 1.016 & 4.838 & 69.752 & 1.101 & 5.242 & 69.752 \\
\hline 10 & .889 & 4.234 & 73.985 & & & & & & \\
\hline 11 & .822 & 3.913 & 77.898 & & & & & & \\
\hline 12 & .691 & 3.292 & 81.191 & & & & & & \\
\hline 13 & .668 & 3.183 & 84.373 & & & & & & \\
\hline 14 & .634 & 3.018 & 87.391 & & & & & & \\
\hline 15 & .543 & 2.584 & 89.975 & & & & & & \\
\hline 16 & .507 & 2.414 & 92.390 & & & & & & \\
\hline 17 & .470 & 2.239 & 94.628 & & & & & & \\
\hline 18 & .368 & 1.752 & 96.381 & & & & & & \\
\hline 19 & .356 & 1.697 & 98.078 & & & & & & \\
\hline 20 & .239 & 1.136 & 99.215 & & & & & & \\
\hline 21 & .165 & .785 & 100.000 & & & & & & \\
\hline
\end{tabular}

Extraction Method: Principal Component Analysis.

Table 4:Rotated Component Matrix ${ }^{a}$

\begin{tabular}{|l|c|c|c|c|c|c|c|c|c|}
\hline & \multicolumn{9}{|c|}{ Component } \\
\cline { 2 - 10 } & 1 & 2 & 3 & 4 & 5 & 6 & 7 & 8 & 9 \\
\hline Car ownership & .832 & .061 & .242 & .175 & .042 & -.168 & -.042 & -.024 & .014 \\
\hline House ownership & .742 & .074 & .102 & .316 & .220 & .004 & -.104 & -.032 & .075 \\
\hline Necessity choice & -.699 & .160 & -.024 & .152 & .268 & -.043 & -.181 & -.206 & .164 \\
\hline Health condition & .076 & .764 & -.106 & -.038 & .076 & -.109 & .093 & -.188 & .088 \\
\hline Family unity togetherness & -.016 & .672 & -.080 & -.128 & .200 & .088 & .009 & .099 & .122 \\
\hline Leisure freedom & -.115 & .560 & .343 & .021 & -.093 & -.043 & .163 & .208 & -.290 \\
\hline Work environment & .075 & .462 & -.233 & .079 & .172 & .429 & -.097 & .269 & -.270 \\
\hline Pension Fund & .149 & .038 & .741 & .192 & -.039 & -.094 & -.174 & -.191 & .039 \\
\hline Medical aid & .246 & -.059 & .719 & .007 & -.311 & .071 & -.128 & -.048 & .024 \\
\hline Debt & -.011 & .263 & -.641 & .267 & -.231 & .108 & -.279 & -.117 & .235 \\
\hline Household durable items & .155 & -.001 & .044 & .849 & -.063 & -.115 & .084 & .098 & .005 \\
\hline Children number & -.167 & .343 & .013 & -.605 & .116 & -.104 & -.055 & .378 & .163 \\
\hline Education & -.027 & .036 & -.005 & -.028 & .779 & .081 & -.139 & .146 & .051 \\
\hline Community friends & .076 & .206 & -.129 & -.090 & .767 & -.011 & .085 & -.108 & -.025 \\
\hline Community programs & .092 & -.005 & -.053 & -.232 & .060 & .763 & .109 & -.102 & .056 \\
\hline Personal growth work & -.348 & -.081 & .050 & .185 & -.025 & .668 & -.024 & -.036 & .085 \\
\hline Income received & -.013 & .273 & -.135 & -.358 & .028 & .380 & -.234 & .344 & -.024 \\
\hline Treat at work & -.011 & .006 & .050 & .237 & .053 & .109 & .826 & .031 & .027 \\
\hline Friends at work & .016 & .222 & -.332 & -.152 & -.189 & -.091 & .663 & -.013 & .024 \\
\hline Religion & .099 & -.006 & -.097 & -.002 & .031 & -.080 & .051 & .903 & .110 \\
\hline Ideas contribution & -.036 & .066 & -.036 & -.042 & .029 & .074 & .044 & .123 & .881 \\
\hline
\end{tabular}

Extraction Method: Principal Component Analysis.

Rotation Method: Varimax with Kaiser Normalization.

a. Rotation converged in 14 iterations.

The second set has four factors (health, family togetherness, leisure and working environment) with loadings 0.764 , $0.672,0.560$ and 0.462 respectively). It has an Eigen value of 2.208 , and it explains $10.5 \%$ of the variation in happiness (Tables 3 and 4). Of these factors, health condition is found to have a greater influence on happiness than leisure. People who are healthier and have a positive work environment are less prone to sickness and appear to be happier than others. People who have more leisure perhaps suffer from fewer health risks and this integrates with their family and work environment, and thus contributes to their happiness.

The third component, consisting of three factors (access to pension fund and medical aid and level of debt, with weightings of 0.741 and 0.719 and -0.641 respectively) explained about $8 \%$ of the variation in happiness (Tables 3 and 4). Having a pension fund and a medical aid facility contributes to financial well-being of a person and both factors are 
almost of equal importance in influencing happiness as their weights are nearly equal to each other. But debt $(-0.641)$ has negative influence on subjective well-being. These factors may be partially related to income, as individuals who are earning low levels of income, may not have access to a medical care facility or an adequate financial provision for a comfortable retirement fund.

They may also try to augment their current consumption and have access to durables to impress others by contracting debt, which impacts negatively on subjective well-being.

The influence of household durable items and children on subjective well-being constitutes the fifth cluster, explaining nearly $7.5 \%$ of the variation in happiness. A rather surprising result emerged from the association between children, durable household items and happiness. Ownership of durable items (materialism) is found to have a stronger influence (loading 0.849) on perceived happiness than children. Having more children in the family is found to be negatively (loading -0.605 ) related to happiness. Having more children may not to add to happiness, as resources have to be spread more thinly when the family size is too large. As this may be an unexpected result in the African tradition, the relationship between household assets, children in the household and happiness is an area that may require further research of a qualitative and interactive approach.

Education and community friendship jointly explain about $7 \%$ of the variation in happiness. More educated people may have more friends and tend be happier than the less educated. Similarly, friendship within the community is found to be an important source of happiness, with almost the same loading $(0.767)$ as that of education $(0.779)$. Hence, both factors are in the same fifth component (Tables 2 and 4).

The sixth set consists of three factors, accounting for about $6.3 \%$ of the variation in subjective well-being. These are: involvement in community programs, experiences of personal growth at the work level and income level with a weighting of $0.763,0.668,0.380$ respectively. Income is found to be having the lowest weight $(0.380)$ in this component. Overall, income has a rather small effect on happiness relative to community involvement and work or social relationships.

Having friends at work and how the members feel they are treated at the work jointly account for about $7 \%$ of the variation in happiness. The loading for treatment at work is 0.826 and friendship at work is 0.663 respectively. Firms have the power to create positive conditions under which individuals can be content, can thrive and realize their potentials. The work atmosphere is thus seen as a critical factor in influencing subjective happiness. A work environment that allows employees the opportunities to contribute their personal ideas to the functioning of the firm adds to staff satisfaction. In this study, the contribution of staff's creative ideas to the work situation accounts for almost $5 \%$ of the variation in happiness. This creativity factor has an Eigen value of 1.016 and a factor loading of 0.888 (Tables 3 and 4). Creativity at work can influence organisational change.

Another standalone factor which accounts for almost $5 \%$ of variation in happiness is religion. This factor has an Eigen value of 1.040 and a loading of 0.903 (Tables 3 and 4). People who are religiously committed and have strong faith in spiritual values are likely to be virtuous in their social relationships and are likely to be healthier and happier. Indeed, this partially supports Rule's (2007) study in South Africa, who also found that religious importance positively affects happiness.

Although nine components emerged as principal happiness factors, the first five are relatively of greater significance, as about $50 \%$ of the variation in happiness is explained by asset ownership and household items, family or social relationships, health, leisure, availability of a pension or medical aid plan, and education. Diener and Seligman (2002) also found that social relationships through satisfying family life, marriage and friendship are most important for high happiness. The work-related factors, such as having friends at work and being treated fairly, and being recognized for ideas generation, jointly explain about a tenth of the variation in happiness. Income does not emerge as the single most important 'predictor' of life satisfaction. Happiness is also about having a satisfying work environment and mutually rewarding relationships at work. However, what people do with their income gained from work, in terms of car and household asset acquisition, as well as savings toward financial wellness in the form of a retirement fund or medical aid, is found to have a key influence on subjective well-being.

\section{Limitations of the Study}

This study is not without limitations. The small sample size, partly due to resource constraints, is a limitation of this study. A larger sample size, consisting of a greater number of entrepreneurs and workers, with an identification of the various functional roles, might strengthen the results. A large sample size might permit a factor analysis for labour and entrepreneurs separately, which was our original intention. Non-significant results, apparently owing to the small sample 
size, prompted an integrated approach.

Secondly, as this study is based in the Pietermaritzburg region, its results cannot be generalised to the wider national context; a broader study that extends to other provinces might provide better estimates of happiness factors. Further, there may be an endogeneity problem in that happiness may be caused by income, and higher income may result from happiness, more so as happier people tend to be more productive, earn more income and take up more challenges that often bring them more happiness. Similarly, happier people are more likely to get married, just as marriage can lead to greater happiness. As this is not about causality, but grouping of similar factors that influence wellbeing, caution must be exercised when one seeks the direction of causality. However, on the basis of certain pointers, which correlate with other studies of a larger sample size, certain tentative recommendations may be inferred. Owing to the above limitations, the results or inferences drawn from the study are to be treated with some caution.

\section{Discussion of Results}

The pursuit of happiness is a primary objective of our human lives. All the things individuals want are typically meant to be the means to the end of happiness. But many individuals cannot find enduring happiness, and there is not a single determinant that exclusively explains overall subjective well-being. Some individuals believe that happiness lies in material possessions, and in the pursuit of money and fame. Many rich people are not necessarily happier than those with less money. This perhaps leads materialistic members to argue that people with money do not know where to purchase happiness. However, many poor people with limited income are happy. As Lyubormirsky (2008) argues, materialism is extrinsic and even when materialistic goals are attained, this achievement does not always increase our subjective well-being. Daniel Kahneman (2012), reasons that many individuals may suffer from a 'focusing illusion', in that they have an exaggerated belief in the ability of more income to increase their happiness. As it turns out, from this study, individuals' asset ownership and relationships at various levels have a much greater effect on our well-being than income.

Higher income may enable an individual to buy material goods, but material possessions do not contribute to lasting happiness. Improvements in income can make people happier for a while, but the effect fades rapidly as aspirations change over time. As people are habituated to different environmental settings, they settle to some base mean level of happiness, in accordance with the set point theory.

Car ownership, house ownership and household items are found to be associated with subjective well-being. In effect, ownership of household durable items is found to have a stronger positive 'signaling' effect (loading 0.849) on happiness, whereas having many children is negatively related to happiness, with a factor loading of -0.605 . This may be so as household items are almost costless to maintain, whereas taking care of children involves a lot of really hard work, lifelong responsibilities and resources, although parenting may have many rewarding moments. Although literature and results of the present study indicate that married people tend to be happier than those who are unmarried or separated, parents often experience lower levels of emotional wellbeing than childless peers.

Ed Diener and Biswas-Diener (2008) add that marital satisfaction dips at the birth of the first child and continues to move down, hitting a low when the children are teenagers, and thereafter improves.

The quality of life and relationships are essential for happiness. As the second component indicates, family unity or togetherness, leisure, health and the work environment are significantly associated with happiness. Of these factors, health is the most important, with a loading of 0.764 . If one has good health one has got one's happiness. Without good health, one is unlikely to enjoy leisure and feel satisfied with the work environment. Research by Sheldon and Lyubomirsky (2009) and Layard (2011) also confirm a strong correlation between health and happiness. Health affects happiness of adults of all ages partly because those in good health simply feel subjectively better able to do the things they want and are more socially and physically active.

Security is important for one's life satisfaction. Individuals feel more secure emotionally and physically when they have a house, as the basic need for shelter is being met. Having a pension fund and a medical aid facility provides another security cover for an individual's wellness and future financial needs when in retirement. Thus, making adequate financial provisions for contingencies and long term needs have a positive influence on subjective well-being, whereas debts that individuals owe have a negative bearing (factor loading of -0.605 ) on life satisfaction.

Education and community friendships are also found to be associated with well-being. Educated people are happier than their less educated counterparts. Education is also linked to higher productivity and income, as well as occupational status. Individuals with greater talents and wider community networks or friendships have wider choices in life and are perceived to be happier relative to those with lower skills or community networks (Putman, 2001; Layard, 
2011). Thus, the building up of human and social capital though better education and friendly relationships within the community and at work are to be encouraged for higher levels of trust and a better quality of life. Societies with more trust and less inequalities have fewer crimes and thus are happier (Wilkinson and Pickett, 2010; Powdthavee, 2011).

Individuals derive satisfaction from work, social relationships and involvement in community programs. In effect, involvement in community programs is found to have a greater loading $(0.763)$ on subjective well-being than income (0.380). This tends to suggest that happy people are content not with idleness or isolation, but as a result of relational activeness in making things happen. Those who are often involved in community programs tend to flow with an activity that enables them to use their talents and resources to make a difference in other people's lives. This has positive implications for managers and business leaders in their quest to optimize employee and enterprise performance. The flow experiences of employees in turn may boost their sense of self-esteem and well-being (Csikszentmihalyi, 1997).

The environment in which one works to earn an income is equally important in contributing to one's happiness. Individuals who have a positive work environment tend to be happier and are prepared to take on additional commitments for the advancement of the firm (Frey and Stutzer,2002; Seligman, 2004). Working in an unfulfilling environment can be very stressful for entrepreneurs and frustrating for employees. Stress at work can transcend into the family environment, impacting adversely on household happiness. It is in the employers' interests to ensure a healthy working environment in which employees are treated fairly and in which they have friendly relationships with other members, and are able to realize their potentials. Work allows members to identify with several communities within and outside the firm. Happy workers are more productive and they absent themselves less frequently from work. Happiness researchers have identified strong causal links running from happiness to business performance (Frey and Stutzer, 2002). Happy workers are better at producing fresh ideas for changing products and services as well as new procedures for enhanced enterprise performance or solving problems in the firm (Diener and Biswas-Diener, 2008).

Religious faith has a profound positive effect on happiness, through companionship, social bonding, and scope for personal and spiritual growth. This factor individually contributes to about $5 \%$ of the variation in reported happiness. One cannot contemplate to be happy when in social isolation. Even Marshall (1890: 2) argued that "in religion, in the family affections and in friendship, even the poor may find scope for.... the highest source of happiness."

\section{Policy Implications}

Happiness is a subjective issue with a multidimensional and multidisciplinary leaning. Income has a direct and an indirect influence on happiness. Money can 'buy' happiness, especially for low-income earners and poor people, whose basic needs are not adequately met. As Kahneman (2012: 396) puts it, being poor makes one miserable, but being rich may enhance one's life satisfaction.

People derive a degree of their satisfaction from how they feel at work, as entrepreneurs and employees. Individuals with better family ties and religious commitments, with few children and friendships, and a good working environment are happier than others where these qualities are lacking. For enhanced subjective well-being, both entrepreneurs and labour should be happier in their work, family and community environments. Employers and managers can create more fulfilling work environments that bring out the best in each member and that allow their employees to contribute ideas for personal development and enterprise growth. Entrepreneurs and business leaders can refine the local work environment, by creating a climate conducive to promoting staff happiness, with 'wellness' factors, such as pensions and medical aid as well as upward career mobility in the venture. Focusing on the human factor can induce commitment of employees, with bottom line improvements. There is no happiness at work or elsewhere without good actions and social relationships (Sheldon and Lyubomirsky, 2009; Putman, 2000). Individuals are thus encouraged to invest in social capital and maintain good social connectedness at work, in the family and partake in regional community projects, as these elements boost economic efficiency and enhance well-being (Sachs, 2012). As Lane (2001) puts it, it is friendship and other social connections at work and in broader community to other human beings that are important contributors to a rewarding and happy life. Put succinctly, "it is family, friends and community that matter to happiness" (Wilkinson and Pickett, 2010: 274).

As education is significantly associated with happiness, it is important for policymakers to implement measures that allow for access to education for all citizens, enabling them to enjoy an empowered quality of life. Expansion of human capability that strengthens employable skills compatible to market needs, not only affords one a higher salary, it also permits the purchase of many pleasures or experiences, and durable items. This enhances an individual's selfesteem and contributes to increase one's level of experienced well-being (Sen, 2010; Kahneman, 2012).

Unhappiness stems from unemployment and high income inequalities (Oswald, 1997; Layard, 2011). For South 
Africa, Hinks and Gruen (2007:326) found that being unemployed has a negative impact on happiness. People can be happier if there are more opportunities for them to gain an income through value-adding activities in the labour market rather than through transfer payments, in the form of social grants. This entails job creation, which can increase with economic growth. Creating new challenging jobs that match the skills profile of labour is essential for a renewed sense of subjective well-being and national prosperity.

While more money can be earned by spending more time at paid work, this could be at the detriment of social and family relationships, if the number of worked hours per week or day is excessively long. Accordingly, there needs to be a balance in allocating one's time between work and leisure, so that 'quality' time is spent on looking after one's health and maintenance of healthy social relationships that result in higher levels of happiness and a better quality of life.

Jackson (2010: 16) reinforces this point, arguing that happiness goes beyond material pleasures; it resides in the quality of our lives, in the health and well-being of our families, in the strength of our relationships and our trust in the community within the ecological limits of a finite planet. He suggests an alternative hedonism - a downshifting lifestyle over time for individuals where the emphasis is on simplicity. This is possible through devoting less time to materialistic pursuits and greater time to other activities, such as gardening, walking, music, reading, religiosity and the care of others, thus pursuing a way of living that is outwardly simple yet inwardly rich (Jackson, 2010: 149). To enhance happiness and lasting prosperity, as Sachs (2012: 165) suggests, we need a "new mindfulness" of self, of work, of knowledge, of others, of nature and of the future, beyond the cravings of wealth, such that there is a balance between consumption and saving, work and leisure, individualism and social relationships.

\section{Conclusion}

The search for a satisfying life of endeavor is an important universal goal. Every individual has the potential to be a happier person and to make others happier too. Married people are significantly happier than others, while no significant difference is found in mean happiness level between male and female. At the broader level, more happiness may come from a sustained growth in GDP that enables households to enjoy an improved quality of life, with rising income and employment opportunities. Having wealth may give an individual a sense of security in the future and an affordability of assets that may contribute to subjective well-being. But income accounts for only a small contribution to happiness.

Life circumstances, such as health, asset ownership, having a pension or medical aid facility, a few children in the household, and a fulfilling work environment can make a great contribution to subjective well-being. Policy makers can enhance wellbeing through improved delivery on education, housing, health, employment and social security.

While happiness can be a genetic aspect of one's personality, people can still become happier if they are educated, have a balanced work-leisure lifestyle and they nurture creativity, spirituality, generosity, and friendly relationships at work, in the family and in the broader community. These actions can impact positively on generating a spirit of trust among individuals at different levels. The more trust there is in social and work relationships, the happier people are likely to be. As Aristotle argues, happiness is a state of virtuous activity that good people do in a society. Doing good makes us feel good, optimistic and happy, as employees and entrepreneurs. Happiness is not to be found outside; it is inside us (Lyubomirsky, 2008). Thus, what matters most to happiness is what good we do to ourselves and others with our resources. Our activities in the present pave the way for future serenity and prosperity.

\section{References}

Biswas-Diener R.M. (2007). Material Wealth and Subjective Well-Being, in The Science of Subjective Well-Being, ed Eid, M. and Larsen, R. J., Guilford Press, London, 307-322.

Bruni L., \& Porta P.L., (2007). Handbook on the Economics of Happiness, Edward Elgar, Cheltenham.

Csikszentmilalyi M., (1997). Flow: The Psychology of Optimal Experience, Basic Books, New York.

Clark A.E., \& Oswald A.J., (1994). Unhappiness and Employment. Economic Journal (104), 648-659.

Coakes S., \& Steed L.K., (2003). SPSS Without Anguish, John Wiley and Sons, Queensland.

Diener E., \& Biswas-Diener R., (2008). Happiness: Unlocking the Mysteries of Psychological Wealth, Blackwell, Malden.

Diener E., \& Seligman M.E.P., (2002). Very Happy People, Psychological Science, 13(1): 81-84.

Dixon H.D. (1997). Controversy: Economics and Happiness, Editorial Note. Economic Journal, 107 (November): 1812-14.

Dutt A.K. (2008). The Dependence Effect, Consumption and Happiness: Galbraith revisited, Review of Political Economy, 20(4): 527-50.

Dutt A.K., \& Radcliff B., (2009). Happiness, Economics and Politics, Edward Elgar, Cheltenham, U.K.

Easterlin R. (1995). Will Raising the Incomes of All Increase the Happiness of All?, Journal of Economic Behaviour and Organisation, 27(1): 35-47.

Easterlin R. (2001). Income and Happiness: Toward a Unified Theory. Economic Journal, July, 111 (473): 465-484. 
Field A. (2009). Discovering Statistics Using SPSS, Sage, London.

Frank R.H. (1999). Luxury Fever, Free Press, New York.

Frey B.S. (2008). Happiness: A Revolution in Economics, MIT Press, Cambridge, MA.

Frey B.S., \& Stutzer A., (2002). What can economists learn from Happiness Research? Journal of Economic Literature, June, $402-435$.

Frey B.S., \& Stutzer A., (2000). Happiness, Economy and Institutions. Economic Journal, 110 (446): 918-938.

Hinks T., \& Gruen C., (2007). What is the structure of South African happiness equations? Evidence from Quality of Life Surveys. Social Indicators Research 82:311-336.

HDR. (2011). Human Development Report 2011: Sustainability and Equity- A Better Future for All, UNDP, Palgrave Macmillan, New York.

James O. (2007). Affluenza, Vermilion, London.

Jackson T. (2010). Prosperity Without growth: Economics for a Finite Planet, Earthscan, London.

Kahneman D. (2012). Thinking, Fast and Slow, Penguin, London.

Kenny C. (2005). Does development make you happy? Subjective Well-being and Economic Growth in Developing Countries, Social Indicators Research, 73: 199-219.

Lane E. (2001). The Loss of Happiness in Market Democracies, Yale University Press, New Haven.

Layard R. (2011). Happiness: Lessons from a New Science, Penguin, London.

Layard R. (2006). Happiness and Public Policy: A Challenge to the Profession. Economic Journal, 116 (March): C24-C33.

Lyubomirsky S. (2008). The How of Happiness, Penguin, New York.

Mahadea D., \& Rawat T., (2008). Income, Growth and Happiness: An Exploratory Study, South African Journal of Economics, 76 (2): 276-290.

Marshall A. (1890). Principles of Economics, Macmillan, London.

$\mathrm{Ng}$ Y-K. (2006). Public Policy Implications of Behavioural Economics and Happiness Studies, in Ng, Y-K and Ho, L.S (eds.) Happiness and Public Policy, Palgrave Macmillan, New York.

$\mathrm{Ng}$ Y-K. (1997). A Case for Happiness, Cardinalism, and Interpersonal Comparability. Economic Journal, 107 (445): $1848-58$.

Nuthall K. (2013). Happy Talk. Accounting and Business International, 09/2013: 15-19.

Oswald A. (1997). Happiness and Economic Performance, Economic Journal, November, 107(445), 1815-1831.

O'Toole J. (2005). Creating the Good Life, Rodale, London.

Pallant J. (2006). SPSS Survival Manual, Open University Press, New York.

Perkins H.W. (1991). Religious Commitment, Yuppie Values, and Well-Being in Post-collegiate Life, Review of Religious Research, 32(2): 244-251.

Porter E. (2011). The Price of Everything, Heinemann, London.

Posel D.R., \& Casale D.M., (2011). Relative Standing and Subjective Well-being in South Africa: The Role of Perceptions, Expectations and Income Mobility, Social Indicators Research, 104 (2): 195-223.

Powdthavee N. (2007). Happiness and the Standard of Living: the case of South Africa, in Handbook on Economics of Happiness, ed. L. Bruni and P.L. Porta, Edward Elgar, MA, USA. 447-486.

Powdthavee N. (2011). The Happiness Equation, Icon Books, London.

Putman R. D. (2000). Bowling Alone, Simon \& Schuster, New York.

Putman R.D. (2001). Social Capital: Measurement and Consequences, Canadian Journal of Policy Research 2(1): 41-51.

Rule S. (2007). Religiosity and Quality of Life in South Africa. Social Indicators Research

81: 417-434.

Sachs J. (2012). The Price of Civilization, Vintage, London.

Scitovsky T. (1992) The Joyless Economy: An Inquiry in Human Satisfaction and Consumer Dissatisfaction, Oxford University Press. Oxford.

Seligman E. P. (2004). Authentic Happiness, Free Press, New York.

Sen A. (2010). The Idea of Justice, Penguin, London.

Sheldon K.M., \& Lyubomirsky S., (2009). Change your actions, not your circumstances: an experimental test of the Sustainable Happiness Model, in Happiness, Economics and Politics, ed. A.K. Dutt and B. Radcliff, 324-342.

Smith A. (1759 [1980]). The Theory of Moral Sentiments, Indianapolis, IN: Liberty Fund.

Stutzer A. (2001). What are the Sources of Happiness? in, Frey B.S (Eds), Inspiring Economics: Human Motivation in the Political Economy (p135-146). Edward Elgar, Northampton.

Todaro M., \& Smith. M. (2011). Economic Development, Addison-Wesley, London.

Veenhoven R. (1993). Happiness in Nations: Subjective Appreciation of Life in 56 Nations, Rotterdam, Erasmus University.

Veenhoven R. (1997). The Utility of Happiness, Social Indicators Research, 20: 333-54.

Veenhoven R. (2012). Happiness in South Africa, World Database of Happiness, Erasmus University Rotterdam, The Netherlands, http://worlddatabaseof happiness.eur.nl, accessed 05/05/12.

Veenhoven R., \& Hagerty M., (2006). Happiness in Nations 1946-2004: A Reply to Easterlin, Social Indicators Research, 79, 421-436.

Wilkinson R., \& Pickett K., (2010). The Spirit Level: Why Equality is Better for Everyone, Penguin, London. 